\section{INTERNAL STRESSES IN METALS AND ALLOYS}

$\mathrm{O}^{\mathrm{N}}$ October 15 and 16, a symposium on internal stresses in metals and alloys was held in the rooms of the Institution of Mechanical Engineers. It was organised by the Institute of Metals, in associa. tion with the Faraday Society, the Institute of Physics, the Institution of Mechanical Engineers, the Iron and Steel Institute, the Physical Society and the Royal Aeronautical Society, and was intended to bring together all classes of investigator interested in the subject, and to enable them to compare their points of view. In this it was quite unexpectedly successful, for the large lecture room of the Institution of Mechanical Engineers was filled throughout the programme, and discussion continued with a reasonably good balance between the different interests for the whole of the allotted time.

The proceedings were opened by Colonel P. G. Gueterbock, president of the Institute of Metals, and were divided into four sessions. The first dealt with the measurement of internal stresses. A considerable number of methods have been employed, but none is really convenient and reliable. The trend of the discussion suggested that for the measurement of the stresses which are broadly distributed through the mass of the metal (the macro or body stresses) the method of suitably cutting the article and measuring the resultant distortions is still the most generally applicable, though it has the disadvantage that it usually involves the destruction of the article. Some speakers thought that the technique of this method has not been adequately studied and developed. The X-ray method emerged as clearly the most suitable for the measurement of stresses which vary considerably within short distances (the micro or structural stresses); while those methods which depend on the measurement of properties such as electrical resistivity, magnetic properties and damping capacity proved to be open to criticism. The existence of variations of these properties can readily be demonstrated, but it is always difficult to decide in a particular case how much of the variation is due to internal stress and how much to other causes. Some time was devoted to the lattice strains detected by $\mathrm{X}$-ray methods in plastically deformed metal. It is coming increasingly to be realized that, on account of its polycrystalline structure, plastically deformed metal is a mass of diverse stresses and strains; that this is also the case in plastically deformed silver chloride was elegantly demonstrated by $\mathrm{Mr}$. J. F. Nye by the use of polarized light.

The afternoon of the first day was devoted to sixteen papers on the origin and control of internal stresses in metals. So many papers could scarcely be discussed fully in one afternoon, but the great variety of the conditions which can give rise to internal stresses in metals was brought out very vividly, and it was possible to pick out those questions which exercise the minds of the engineer and metallurgist at the present time. The possibility that internal stresses may cause distortions in components of high-speed machinery is a source of anxiety, for lack of balance can induce dangerous stresses; and it is more than likely that some special treatments designed to give strength or toughness result in higher internal stresses than should be tolerated. In some aluminium alloys the treatment which gives the freedom from internal stresses may result in liability to stress corrosion effects, and a nicely balanced treatment is necessary if the producer is to err on neither side. The last word has not yet been said on the influence of the stresses left behind by the welding process, and although there is no evidence that they are necessarily harmful, most engineers prefer to remove them if it is at all possible. On the other hand, the advantages to be obtained by deliberately introducing compressive stresses at the surface of components are regarded as demonstrated; but it is also felt that more, and more complete, data are needed on the effect of these stresses on the fatigue limit of the component.

The second morning was devoted to the effects upon metals of the stresses distributed on a microscopic scale, and produced a general discussion of the theory of the strength of metals. Sir Lawrence Bragg opened with an attractive development of his theory of the effect of crystallite size on strength, and emphasizing the necessity of thinking in terms of strain rather than of stress, directed attention to the great difference in the mobilities of simple and complex faults in crystal lattices. Several speakers referred to the uncertainty of present measurements of crystal. lite size, and the ultimate conclusion appeared to be that measurements of crystallite size, X-ray line broadening and mechanical properties are wanted, carried out on the same specimens, and under widely varying conditions. A recurrence of interest in the conditions at grain boundaries was noticeable, and the vexed question of the ability of dissolved hydrogen to burst solid steel, which is so important in connexion with the defects known as hair-line cracks, was also debated. In this argument, much depends on what is assumed about the molecular condition at room temperature of the dissolved hydrogen, on which subject we are still insufficiently well informed. Little disagreement is now expressed about the origin of the internal stresses associated with reactions in the solid state, such as precipitation hardening and the formation of martensite. The complementary question of the effect of stresses on the course of the transformations is not so clear, the distinction between the effects of stress and of plastic deformation not always having been kept in mind.

The final discussion, which dealt with the effects of stresses distributed on a macroscopic scale, was largely concerned with stress corrosion cracking, and revealed a considerable unanimity of opinion. There were differences in the estimates of the susceptibility of different materials to this type of failure, and of the importance of particular factors ; but all speakers agreed that corrosive conditions favourable to the production of localized pits, together with sufficient tensile stress at the surface of the metal to cause plastic deformation at the roots of the pits, are the essential factors. The well-known cracking of certain stressed metals in the presence of molten tin or lead does not, however, fit very well into this picture. A second theme which ran through this discussion was the spontaneous cracking which sometimes occurs in steels, particularly hard steels, in the presence of high internal stresses. Mr. J. F. Russell showed some very impressive examples of such ruptures in large steel ingots and Iforgings, but in practice the phenomenon has occurred chiefly in welded hard steel plates, and has caused some anxiety. Corrosion appears not to be concerned in this case, and the reason why the cracks appear only after the lapse of time is not yet clear. The cracks can, however, be prevented by suitable choice of the 
composition of the steel, and, more important, by ensuring that the steel is not put into use in an excessively hard condition.

In all, thirty-six papers were presented at the symposium and these, together with a report of the discussions, will be published in the Special Reports and Monographs series of the Institute of Metals. The symposium left a strong impression of the diversity and importance of the problems associated with internal stresses in metals, and the published account will prove to be a most valuable source of information.

\section{GROUND BLOCKS OF THE CONTINENTS AND OCEAN BOTTOMS*}

\author{
By Prof. H. CLOOS \\ Geologisch-palæontologisches Institut, Bonn
}

$\mathrm{D}$ URING the last twenty or thirty years, the scientific conceptions of the structure and development of the earth's crust have been widely influenced, if not dominated, by the Wegener theory of continental drift and by the idea of orogenetic phases dividing the structural history into short but world-wide times of movement separated by intervals of rest or of mere 'epeirogenetic' oscillations. The first theory disrupted the lateral, the second one the vertical (temporal) connexions. But within the same decades, the growth of geological knowledge of nearly all continents, combined with the results of submarine and even of geophysical investigations, pointed in another direction. They led to the conclusion that the major structural zones and units of the earth are much older than they formerly seemed, and that they indicate a long and strong continuity from the very first stages of the globe up to the present. It seems that from early geological time, the crust has been divided into polygonal fields or blocks of considerable thickness and solidity, and that this primary division formed and orientated the later movements.

My own contributions to this extensive problem date from 1910, when I first investigated the influence of old Tertiary faults upon young Tertiary folds within the Swiss Jura Mountains near Basle. Later on they dealt with the Rhinegraben, with the primary limits of the Rhenish Schiefergebirge, the Precambrian stages of important block boundaries in Norway and Sweden, with the conservative develop. ment of Silesia and the Bohemian mass, with the Harz Mountains, with North-East and South Africa, with certain areas in North America, and the Atlantic structure, the Azores and the Red Sea. Among the many important observations of other scientific investigators in different countries, Dixey's discovery of an older Nyasa fault-trough in Africa is the latest but not the least. Sonder, in his papers on Europe and Central America, laid stress upon the straight direction of certain old and persistent lineaments.

To start with the blocks, or fields, themselves, their limiting walls are to be considered as thick zones of a highly variable behaviour and history,

- Summary of the presidential address given to the annual meeting of the Geologisehe Vereinigung at Bonn on April 29, 1947, under the tifle, "Die Grundschollen der Festländer und Meere. Entwurf eines ronservativen Erdbildes"; a detailed account is being published in the Geologische Rundschau, Stuttgart, No. 2 (1947). and should be called 'geofractures' or 'geosutures', analogous to the similar terms 'geosynclines' and 'geanticlines'.

The critical features of these ancient and deep units and of their limiting zones are: (1) stratigraphical traces of tectonic movements in earlier geological times; (2) the connexion with plutonio and volcanic activity in early and recent times, etc. ; (3) their relations to deep-seated earthquakes of linear arrangement (down to 500 or even $700 \mathrm{~km}$.) ; (4) the length of the limiting zones (up to several thousand kilometres); (5) the size of the blocks, which varies between 500 and 1,200 or even 1,500 $\mathrm{km}$. in diameter. My experiments and the known physical and technical observations show that there exists a geometrical relationship between the mutual distances of the dissecting joints and the thickness of the dissected sheet.

The crust pattern formed by these ancient geosutures displays several astonishing regularities. Within the three northern continents, blocks of north-south trend limited by meridional sutures are predominant. In North America, eight such fields can be counted; in Europe, eight north of the young mountain ranges in the south; in Asia, a few more. In the Mediterranean girdle, east-west zones prevail. On the Atlantic bottom, longitudinal zones of oblique directions are well known. Their analogy and connexion with terrestrial zones lead to the conclusion that they are the submarine representations of the ancient continental lines. It seems that many continental slopes belong to the deepest, oldest and most important block boundaries, an opinion already included in the well-known theory of the 'permanence' of the continents and oceans.

As areas of different horizontal and vertical dis. placement, the great thick permanent ground blocks influence the sedimentation on their upper surface, and also the magmatic cycles on their under surface within their interior and along their limiting walls. Being older than most of the other tectonic features of the globe, they influence the preparation, the origin and the development of the folded mountain ranges as well. Roughly speaking, within the two main thermodynamic girdles, each block has its own folded range. The structural relations between the younger folding and the older configuration of the respective blocks vary broadly according to the direction of the folding movement relative to the pre-shaped contour of the field. Longitudinal ranges, for example, are usually straight (Urals). Transverse ranges are suspended between the marginal sutures either as garlands or festoons, or in a sigmoidal manner or both (Füllhorn of the Alps). Thus attempts to unite the different folded arcs into uniform and endless 'slings' can be replaced by their individual adaptation to pre-existing units of the crust.

In certain examples, the deformation of a broad superficial area (like the Rocky Mountains in the United States or the corresponding area in Western Europe) can be derived from a more or less homogeneous deformation (for example, a simple torsional shear) of the supporting block. In a recent experi. ment I succeeded in imitating the structure of the Rocky Mountains. A sheet of liquid clay lies on a square wire net. Films of thin paper impregnated with water lie closely on the smoothed surface of the clay. A minute torsion of the wire net suffices to produce the Rocky Mountain uplifts with their typical details and their oblique arrangement. The mutual distances of the individual uplifts are pro. 